\title{
Brugada ECG Sign at Chest Pain Mimicking ST Elevation Myocardial Infarction
}

\author{
Omar Mousa,' Haroonur Rashid²
}

\begin{abstract}
Background: Management of patients with the brugada ECG sign who have no previous history of syncope is still negotiable. We present a case of a 57 year-old Caucasian lady who presented to the emergency department with substernal chest pain. Results: Her past medical history showed that she had two previous episodes of lightheadedness, but no syncope. She had a family history of sudden death secondary to unknown cause in her aunt at the age of 61. Physical exam was unremarkable except for diaphoresis. Electrocardiography (ECC) showed ST elevation in the right precordial leads ( $\left.\mathrm{V}_{1}-\mathrm{V}_{2}\right)$ with T inversion, mimicking a STEMI. Emergent cardiac catheterization revealed normal coronary arteries. Echocardiogram was normal. Again, interpretation of ECG revealed a Brugada type 1 pattern, characterized by coved-type, gradually descending ST-T segment, elevated J point of more than $2 \mathrm{~mm}$ and T wave inversion. Electrophysiological (EPS) testing with a Sodium channel blocker challenge showed a persistent Brugada type 1 pattern with non-inducible ventricular tachycardia. This patient had Brugada type 1 ECG pattern with no previous history of syncope (asymptomatic). Thus she was considered at low risk of developing a serious arrhythmogenic event in the future. Conclusion: A history of syncope remains the best available predictor for arrhythmogenic events. EPS testing in such patients, to stratify the risk and predict for any future events, is still controversial. It is still unjustified to place an implantable cardioverter-defibrillator in asymptomatic non-inducible individuals with the Brugada pattern. These patients should follow up closely with a cardiologist and be aware of the risk of possible triggers of ventricular arrhythmias.
\end{abstract}

Key Words: Brugada syndrome, sudden cardiac death, myocardial infarction, sodium channels, cardiac electrophysiologic technique (Source: MeSH-NLM)

About the Author:

Omar Mousa is an Internal Medicine resident at State University of New York Upstate Medical University, Syracuse, NY, USA

\section{Introduction}

The Brugada pattern is characterized by ECG changes alone, without any of the clinical features of Brugada Syndrome. The ECG changes can be one of three types and can be dynamic. However, the patient should have the type 1 ECG pattern "coved-type" to make the diagnosis of Brugada. The following case report and discussion focuses on the presentation, diagnosis, management and prognosis of the asymptomatic patient with a Brugada ECG pattern.

\section{The Case}

A 57-year-old Caucasian lady presented to the emergency department (ED) with substernal chest pain of one day duration. It was associated with headache, backache and mild dyspnea. She reported 2 episodes of lightheadedness in the past month when she felt she was about to pass out. The episodes lasted for a few seconds and were relieved spontaneously. She denied syncope, dizziness, cough, palpitations, nausea or vomiting.
Her past medical history included hypertension, migraine, depression, attention deficit hyperactivity disorder, chronic sinusitis and asthma. Her home medications included lisinopril, gabapentin, trazodone, adderall, celebrex and flovent diskus. She has history of allergy to codeine sulfate. Her family history included hypertension and coronary artery disease, however it was significant for sudden death of unknown cause in her aunt at the age of 61. She also had a 48-pack-year history of smoking, but quit 7 years ago. She used to work as a hairstylist and consumed alcohol occasionally.

On physical examination, the patient was diaphoretic and in moderate distress in the ED. The ECG was interpreted by the on-call ER physician as a STEMI (Figure 1) and the cardiac catheterization team was activated. Coronary angiography revealed normal coronary arteries. Laboratory results revealed hypokalemia $\mathrm{K}=2.9$, and otherwise normal CBC, cardiac enzymes and other electrolytes. Transthoracic echocardiography showed a normal left ventricular ejection fraction and no structural heart disease. 
Figure 1. Electrocardiography of 57 years-old lady showing a Brugada type 1 pattern, characterized by the coved-type, gradually descending ST-T segment elevation, J wave and $\mathrm{T}$ inversion in leads $\mathrm{V}_{1}-\mathrm{V}_{2}$ and incomplete RBBB in the emergency department.

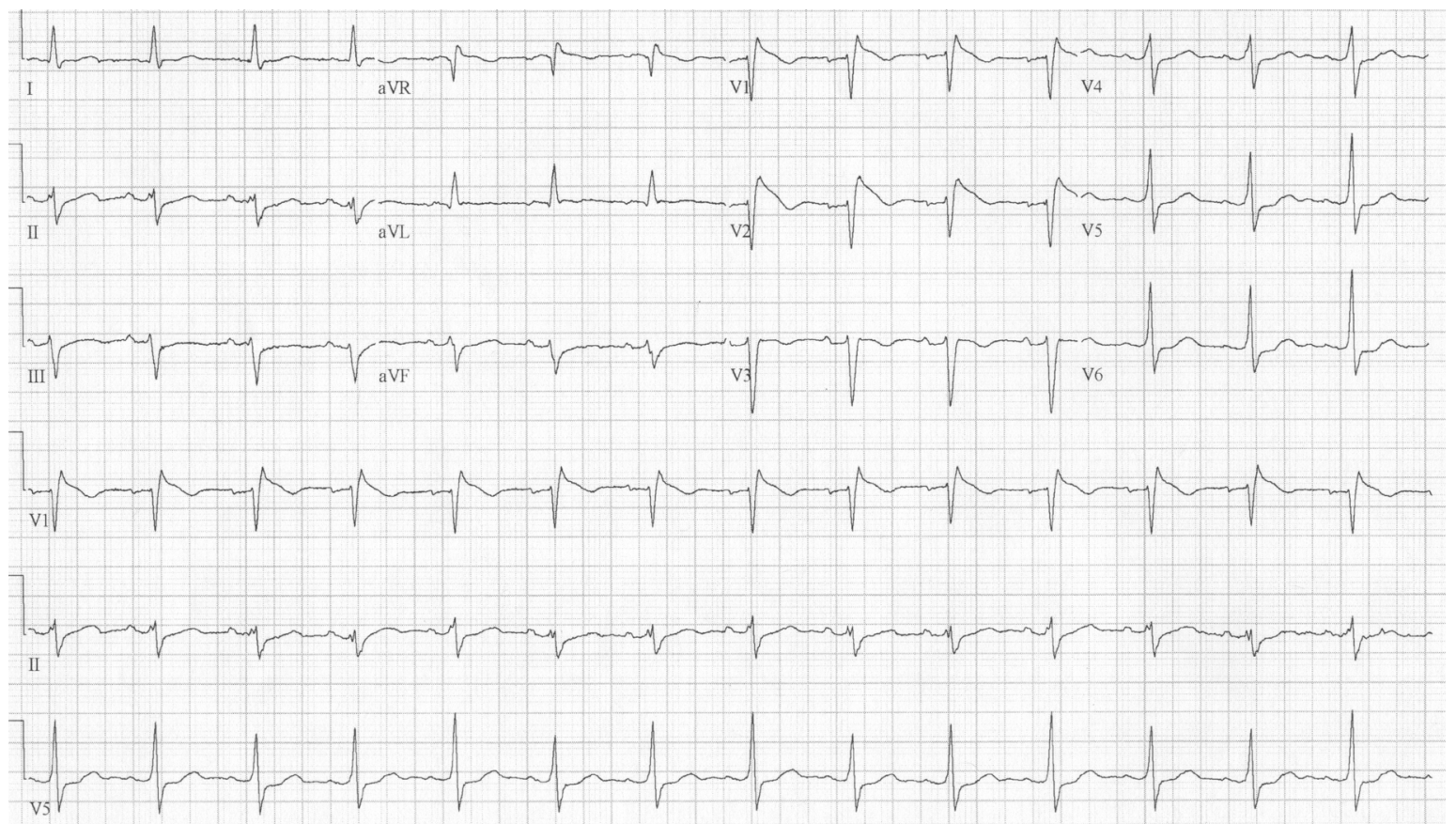

Figure 2. Electrocardiography of the same lady showed a persistent Brugada type 1 ECG pattern on the 5 th day of admission. The patient was afebrile and recovering from a community acquired pneumonia on antibiotics.

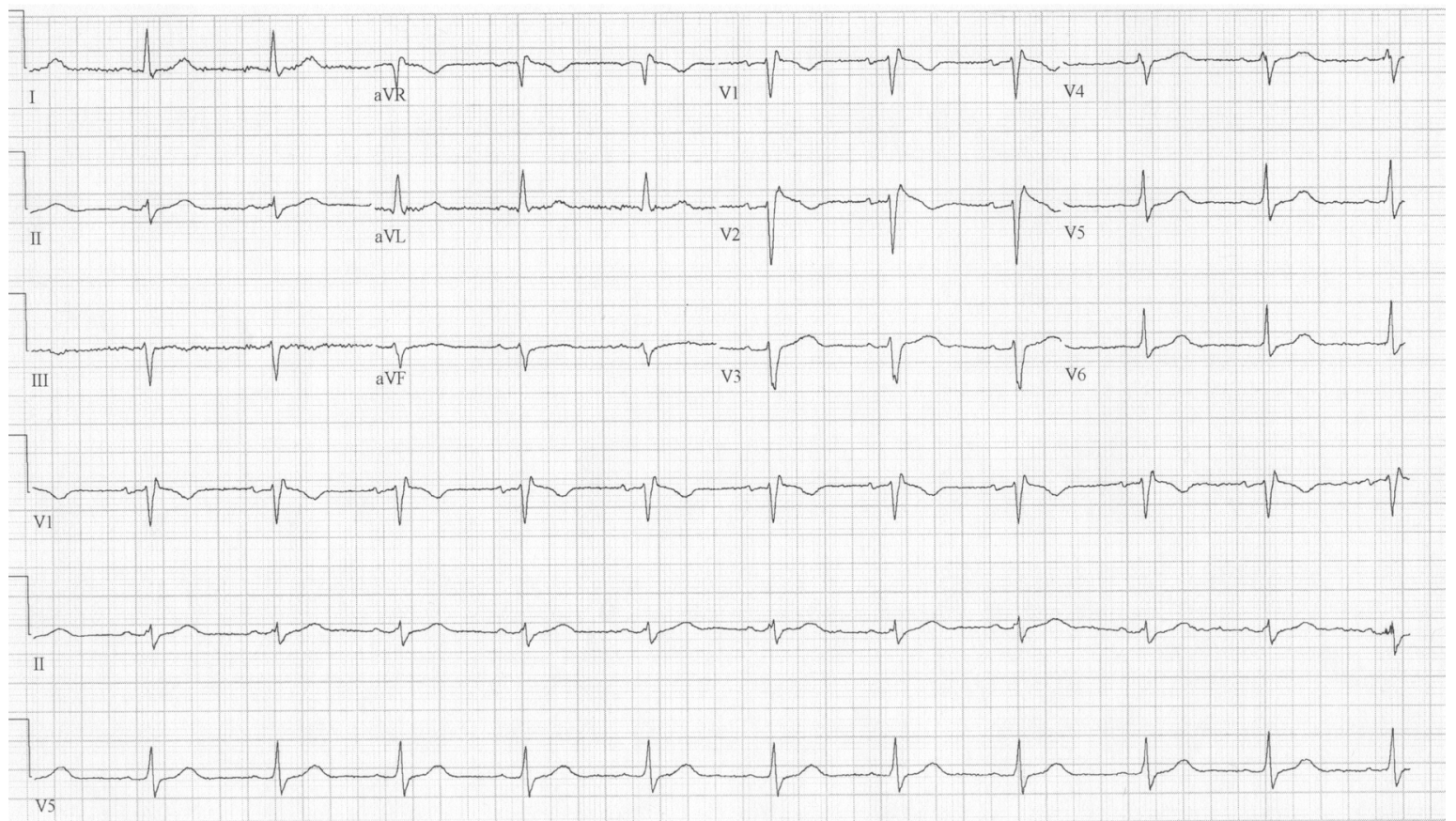

The electrophysiology service was consulted and reevaluation of the ECG revealed coved-type J point and ST elevation in the right precordial leads $\left(V_{1}-V_{2}\right)$ with incomplete right bundle branch block (RBBB), illustrating Brugada type 1 pattern. Cardiac MRI study showed no evidence of arrhythmogenic right ventricular dysplasia (ARVD). Genetic testing for $\mathrm{SCN}_{5} \mathrm{~A}$ mutation wasn't performed.
The patient was transferred to telemetry for observation. Electrophysiological study (EPS) was planned for the next day due to a Brugada type 1 pattern on ECG with nonsustained ventricular tachycardia, when the patient was found to have fever (101.2 F), tachycardia, shortness of breath and cough. 
Physical examination and chest X-ray showed left lower lobe infiltrate with left pleural effusion. Labs showed leukopenia and a positive urine test for the Streptococcus pneumonia antigen. She was diagnosed with community acquired pneumonia and antibiotics were started.

On the 6th day of admission, the patient was doing well and afebrile. A persistent Brugada type 1 ECG pattern is shown in (Figure 2). EPS was performed with provocative testing using procainamide. It revealed Brugada type 1 ECG pattern but no VT was induced with up to triple ventricular extra stimuli from right ventricular apex and base, on and off isuprel. The patient was asymptomatic and no implantable cardioverter defibrillator (ICD) was implanted. She was discharged home and scheduled to follow up closely with her cardiologist.

\section{Discussion}

Sudden cardiac death (SCD) in patients with normal hearts is an uncommon occurrence.' Brugada syndrome (BrS) was described in 1992 as one of the causes of SCD in patients with normal heart structure. ${ }^{2,3}$ This syndrome of high incidence of life-threatening ventricular arrhythmias is associated with ECG changes consistent with ST segment elevation in leads $V_{1}$ to $V_{3}$ and incomplete right bundle branch block. ${ }^{2,4-6}$ Due to the availability of a preventable mode of therapy, an implantable cardioverter-defibrillator (ICD) should be considered when definitive diagnosis of BrS is made.?

The Brugada pattern is characterized solely by the typical Brugada ECG changes, excluding the following clinical features: documented ventricular fibrillation (VF), selfterminating polymorphic ventricular tachycardia (VT), family history of SCD at the age $<45$ years, type 1 ST segment elevation in family members, electrophysiologic inducibility of VT, unexplained syncope suggestive of tachyarrhythmia or nocturnal agonal respiration. The Brugada ECG pattern has a coved-type, gradually descending ST-T segment, J wave amplitude of more than $2 \mathrm{~mm}$ and T wave inversion. ${ }^{8,9}$ Characteristics of patients with the Brugada ECG pattern included higher prevalence in the Asian population. ${ }^{6}$ However, the exact prevalence varied among studies from different countries. ${ }^{13,14,18-21}$ It was mainly observed in adult males ${ }^{19,22}$ and a mutation in $\mathrm{SCN}_{5} \mathrm{~A}$ gene on chromosome 3p21-24, that codes for the alpha-subunit of cardiac sodium channels, was found in about $18-30 \%$ of families with BrS. ${ }^{11,15,23,24}$

The relation between the Brugada ECC sign in asymptomatic patients (no previous history of syncope) and the future risk of developing arrhythmogenic events has been investigated, especially over the past decade. One study revealed that the cardiac event rate per year in asymptomatic patients was $0.5 \%$, compared to $1.9 \%$ in patients with a history of syncope and $7.7 \%$ in patients with aborted SCD. ${ }^{10}$ Further reports of extended follow up of the asymptomatic population over a period of 3 to 7 years showed none to a very low arrhythmogenic event rate..$^{4,9,11-15}$ Variations in the baseline characteristics of asymptomatic patients over a mean follow up of 2 to 3 years, revealed different rates of arrhythmias, with events arising in $8 \%$ of the asymptomatic population studied by Brugada et $a l,{ }^{16,17}$ compared to $0.8 \%$ in a later study by Eckardt et al. ${ }^{17}$

Multiple predictors of future arrhythmic events in patients with the Brugada pattern were studied, with male gender, mutation of the $\mathrm{SCN}_{5} \mathrm{~A}$ gene and a positive family history of SCD found to be non-predictive. ${ }^{10,16,30}$ The prognostic value of the clinical, ECG and EPS variables was analyzed in a population of spontaneous type 1 Brugada ECC patterns and no previous cardiac arrest. The cohort with negative EPS (non-inducibility of VT/VF) had a $1.8 \%$ risk of developing arrhythmic events (SCD or documented VF), compared to $14 \%$ in those with a positive EPS. ${ }^{30}$ Further studies revealed a $0.9 \%$ rate of significant cardiac events in patients with non-inducible arrhythmias. ${ }^{16,31}$ A recent prospective multicenter study showed that a positive EPS is not predictive for arrhythmic events, and data reported that the spontaneous ECG pattern and the history of syncope are the best available predictors of such events..$^{10,32}$ It also showed that QRS fragmentation and a ventricular effective refractory period of less than 200ms are risk indicators. These findings are imperative indicators for the need of an implantable cardioverter defibrillator in such populations. ${ }^{32}$ Additional literature review revealed the low significance of EPS in stratifying the risk of future arrhythmic events, and that its role remains an area of investigation and debate. , $^{11,15-17,26,33-39}$

Currently, pharmacological therapy for the prevention of SCD in Brugada patients is not well established, however some reports showed that quinidine and hydroquinidine may be beneficial in such patients. ${ }^{40-43}$ The ICD has multiple complications, including the relatively high rate of inappropriate shocks (6-9\% per year), thus it seems to be unjustified to give an ICD to the asymptomatic noninducible individual with an abnormal ECG pattern. . $6,23,44-46^{-1}$ There is no definite evidence to suggest that individuals who have no personal history of syncope or any family history of SCD are at a higher risk of SCD than the general population. $4,9,11-13,15$

In our case, genetic testing was deferred as only a small percentage of patients with the BrS do test positive for the $\mathrm{SCN}_{5} \mathrm{~A}$ gene mutation, ${ }^{9,11}$ and recent reports showed that it will not guide the management of such cases. ${ }^{25}$ We excluded other important causes of SCD, including ARVD, where the Brugada ECG pattern can be an early subclinical manifestation of this genetic disorder. ${ }^{26}$ Moreover, our patient was afebrile on presentation and didn't have any of the known provoking factors that induce a Brugada-like 
ECG pattern. ${ }^{27,28,29}$ There was no previous history of syncope along with non-inducible VT on provocative EPS testing. Lack of such possible predictive factors reflects a low risk of developing arrhythmic events and SCD..$^{30}$ Thus ICD therapy wasn't recommended in this lady as the weight of evidence didn't support it.? To conclude, our patient was advised to follow up carefully with the cardiologist and to be aware of the risks of possible triggers of ventricular arrhythmias.

\section{References}

1. Chugh SS, Kelly KL, Titus JL. Sudden cardiac death with apparently normal heart. Circulation 2000;102(6):649-54

2. Brugada P, Brugada J. Right bundle branch block, persistent ST segment elevation and sudden cardiac death: a distinct clinical and electrocardiographic syndrome. A multicenter report. J Am Coll Cardiol 1992; 20(6):1391-6.

3. Scherr D, Brunner $G$, Kaufmann $P$, et al. Aborted sudden death in a patient with a structurally normal heart: the Brugada syndrome. Intensive Care Med 2002;28(6):789-92.

4. Atarashi $\mathrm{H}$, Ogawa S, Harumi $\mathrm{K}$, et al. Characteristics of patients with right bundle branch block and ST-segment elevation in right precordial leads. Idiopathic Ventricular Fibrillation Investigators. Am J Cardiol 1996;78(5):581-3.

5. Brugada J, Brugada P. What to do in patients with no structural heart disease and sudden arrhythmic death? Am J Cardiol 1996;78(5A):69-75

6. Alings M, Wilde A. "Brugada" syndrome: clinical data and suggested pathophysiological mechanism. Circulation 1999;99(5):666-73. 7. Epstein AE, DiMarco JP, Ellenbogen KA, et al. ACC/AHA/HRS 2008 Guidelines for Device-Based Therapy of Cardiac Rhythm Abnormalities: a report of the American College of Cardiology/American Heart Association Task Force on Practice Guidelines (Writing Committee to Revise the ACC/AHA/NASPE 2002 Guideline Update for Implantation of Cardiac Pacemakers and Antiarrhythmia Devices): developed in collaboration with the American Association for Thoracic Surgery and Society of Thoracic Surgeons. Circulation 2008; 117(21):e350-480. 8. Wilde AA, Antzelevitch C, Borggrefe $M$, et al. Proposed diagnostic criteria for the Brugada syndrome. Eur Heart J 2002;23(21):1648-54.

9. Littmann L, Monroe MH, Kerns WP, Svenson RH, Gallagher JJ. Brugada syndrome and "Brugada sign": clinical spectrum with a guide for the clinician. Am Heart J 2003;145(5):768-78.

10. Probst V, Veltmann C, Eckardt L, et al. Long-term prognosis of patients diagnosed with Brugada syndrome. Results from the FINGER Brugada Syndrome Registry. Circulation 2010;121(5):635-43.

11. Priori SG, Napolitano C, Gasparini M, et al. Clinical and genetic heterogeneity of right bundle branch block and ST-segment elevation syndrome: A prospective evaluation of 52 families. Circulation 2000;102(20):2509-15.

12. Takenaka S, Kusano KF, Hisamatsu K, et al. Relatively benign clinical course in asymptomatic patients with Brugada-type electrocardiogram without family history of sudden death. J Cardiovasc Electrophysiol 2001;12(1):2-6

13. Miyasaka Y, Tsuji H, Yamada K, et al. Prevalence and mortality of the Brugadatype electrocardiogram in one city in Japan. J Am Coll Cardiol 2001;38(3):771-4 14. Atarashi H, Ogawa S, Harumi K, et al. Three-year follow-up of patients with right bundle branch block and ST segment elevation in the right precordial leads: Japanese Registry of Brugada Syndrome. Idiopathic Ventricular Fibrillation Investigators. J Am Coll Cardiol 2001;37(7):1916-20.

15. Priori SG, Napolitano C, Gasparini M, et al. Natural history of Brugada syndrome: insights for risk stratification and management. Circulation 2002;105(11):1342-7.

16. Brugada J, Brugada R, Antzelevitch C, et al. Long-term follow-up of individuals with the electrocardiographic pattern of right bundle-branch block and STsegment elevation in precordial leads $V_{1}$ to $V_{3}$. Circulation 2002;105(1):73-8.

17. Eckardt L, Probst V, Smits JP, et al. Long-term prognosis of individuals with right precordial ST-segment-elevation Brugada syndrome. Circulation 2005;111(3):257-63.

18. Matsuo K, Akahoshi M, Nakashima E, et al. Clinical characteristics of subjects with the Brugada-type electrocardiogram. J Cardiovasc Electrophysiol 2004;15(6):653-7.

19. Matsuo K, Akahoshi M, Nakashima E, et al. The prevalence, incidence and 
prognostic value of the Brugada-type electrocardiogram: a population-based study of four decades. J Am Coll Cardiol 2001;38(3):765-70.

20. Junttila MJ, Raatikainen MJ, Karjalainen J, et al. Prevalence and prognosis of subjects with Brugada-type ECG pattern in a young and middle-aged Finnish population. Eur Heart J 2004;25(10):874-8.

21. Monroe MH, Littmann L. Two-year case collection of the Brugada syndrome electrocardiogram pattern at a large teaching hospital. Clin Cardiol 2000;23(11):849-51.

22. Di Diego JM, Cordeiro JM, Goodrow RJ, et al. Ionic and cellular basis for the predominance of the Brugada syndrome phenotype in males. Circulation 2002;106(15):2004-11.

23. Antzelevitch C, Brugada P, Borggrefe M, et al. Brugada syndrome: report of the second consensus conference: endorsed by the Heart Rhythm Society and the European Heart Rhythm Association. Circulation 2005;111(5):659-70.

24. Chen Q, Kirsch GE, Zhang D, et al. Genetic basis and molecular mechanism for idiopathic ventricular fibrillation. Nature 1998;392(6673):293-6.

25. Cehi AK, Duong TD, Metz LD, Comes JA, Mehta D. Risk stratification of individuals with the brugada electrocardiogram: A meta-analysis. J Cardiovasc Electrophysiol 2006;17(6):577-83.

26. Gussak I, Antzelevitch C, Bjerregaard P, et al. The Brugada syndrome: clinical, electrophysiologic and genetic aspects. J Am Coll Cardiol 1999;33(1):5-15.

27. Amin AS, Meregalli PG, Bardai A, Wilde AA, Tan HL. Fever increases the risk for cardiac arrest in the Brugada syndrome. Ann Intern Med 2008;149(3):216-8. 28. Rouleau F, Asfar P, Boulet $S$, et al. Transient ST segment elevation in right precordial leads induced by psychotropic drugs: relationship to the Brugada syndrome. J Cardiovasc Electrophysiol 2001;12(1):61-5.

29. Coldgran-Toledano D, Sideris G, Kevorkian JP. Overdose of cyclic antidepressants and the Brugada syndrome. N Engl J Med 2002;346(20):1591-2. 30. Brugada J, Brugada R, Brugada P. Determinants of sudden cardiac death in individuals with the electrocardiographic pattern of Brugada syndrome and no previous cardiac arrest. Circulation 2003;108(25):3092-6.

31. Ikeda T. Brugada syndrome: current clinical aspects and risk stratification. Ann Noninvasive Electrocardiol 2002;7(3):251-62.

32. Priori SG, Gasparini M, Napolitano C, et al. Risk stratification in Brugada syndrome: results of the PRELUDE (PRogrammed ELectrical stimulation preDictive valuE) registry. J Am Coll Cardiol 2012;59(1):37-45.

33. Paul M, Gerss J, Schulze-Bahr E, et al. Role of programmed ventricular stimulation in patients with Brugada Syndrome: a meta- analysis of worldwide published data. Eur Heart J 2007;28(17):2126-33

34. Gussak I, Bjerregaard P, Hammill SC. Clinical diagnosis and risk stratification in patients with Brugada syndrome. J Am Coll Cardiol 2001;37(6):1635-8.

35. Takenaka S, Emori T, Koyama S, et al. Asymptomatic form of Brugada syndrome. Pacing Clin Electrophysiol 1999;22(8):1261-3.

36. Brugada P. Brugada syndrome: an electrocardiographic diagnosis not to be missed. Heart 2000;84(1):1-2

37. Brugada P, Brugada R, Brugada J, Geelen P. Use of the prophylactic implantable cardioverter defibrillator for patients with normal hearts. Am J Cardiol 1999;83(5B):98D-100D

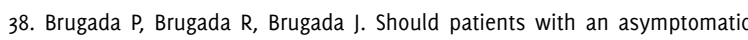
Brugada electrocardiogram undergo pharmacological and electrophysiological testing? Circulation 2005;112(2):279-92.

39. Priori SG, Napolitano C. Should patients with an asymptomatic Brugada electrocardiogram undergo pharmacological and electrophysiological testing? Circulation 2005;112(2):279-92.

40. Belhassen B, Glick A, Viskin S. Efficacy of quinidine in high-risk patients with Brugada syndrome. Circulation 2004;110(13):1731-7.

41. Belhassen B, Viskin S, Fish R, Glick A, Setbon I, Eldar M. Effects of electrophysiologic-guided therapy with Class IA antiarrhythmic drugs on the long-term outcome of patients with idiopathic ventricular fibrillation with or without the Brugada syndrome. J Cardiovasc Electrophysiol 1999;10(10):130112.

42. Viskin S, Wilde AA, Tan HL, Antzelevitch C, Shimizu W, BelhassenB. Empiric quinidine therapy for asymptomatic Brugada syndrome: Time for a prospective registry. Heart Rhythm 2009;6(3):401-4.

43. Rosso R, Click A, Clikson M, et al. Outcome after implantation of ICD in patients with Brugada syndrome: a multicenter Israeli study (ISRABRU) Isr Med AssoC J 2008;10(6):435-9.

44. Brugada J, Brugada R, Brugada P. Right bundle-branch block and ST-segment elevation in leads $V_{1}$ through $V_{3}$ : a marker for sudden death in patients without demonstrable structural heart disease. Circulation 1998;97(5):457-60. 45. Sacher F, Probst V, lesaka $Y$, et al. Outcome after implantation of a cardioverter-defibrillator in patients with Brugada syndrome: a multicenter study. Circulation 2006;114(22):2317-24.

46. Sarkozy A, Boussy T, Kourgiannides G, et al. Long-term follow-up of primary prophylactic implantable cardioverter-defibrillator therapy in Brugada syndrome. Eur Heart J 2007;28(3):334-44.

\section{Acknowledgements \\ None.}

Conflict of Interest Statement at Funding

The Authors have no funding, financial relationships or conflicts of interest to disclose.

Cite as:

Mousa 0, Rashid H. Brugada ECG Sign A Chest Pain Mimicking ST Elevation Myocardial Infarction. Int J Med Students. 2013;1(2):86-90. 